\title{
Modelling flood hazard at Paratrechos/Peritsi stream, Naxos Island (Cyclades, Greece)
}

\author{
Niki EVELPIDOU ${ }^{1 *}{ }^{*}$ Niki POLYKRETI $^{1}$, Anna KARKANI ${ }^{1}$, Eirini KARDARA ${ }^{1}$, Stamatina SEFERLI ${ }^{2}$, \\ Theofilos VALSAMIDIS ${ }^{1}$ \\ ${ }^{1}$ Faculty of Geology and Geoenvironment, National and Kapodistrian University of Athens, \\ Panepistimiopolis 15784, Athens, Greece \\ ${ }^{2}$ School of Mining and Metallurgical Engineering, National Technical University of Athens, Greece
}

Received 8 August 2018; Revised 30 October 2018; Accepted 15 November 2018

*Correspondence to: Niki EVELPIDOU, e-mail: evelpidou@geol.uoa.gr

\begin{abstract}
Flash floods are one of the most significant natural hazards in the Mediterranean, affecting most basins in the region. Flash floods usually occur in ephemeral streams after particularly heavy rainfall. Although the average annual rainfall in the Cycladic islands (Greece) does not exceed $400 \mathrm{~mm}$, flash floods are frequent, since most of that rainfall is often concentrated in few but very intense events. The case study is the drainage basin of Paratrechos or Peritsi stream in Naxos Island. This particular basin was selected due to the recorded flood events, the stream's proximity to the city that intensifies the flood impact, the slopes' gradient abrupt changes and the diverse infiltration rate of the geological formations. Furthermore, some parts of the basin are intact by human activities, while others are severely affected. This study investigates the relationship between rain and runoff through Unitary Hydrographs, in order to estimate and evaluate the flood potential of the aforementioned hydrologic basin and to determine the causes of the hazard and vulnerability. The Clark method was implemented and its results were further evaluated by field measurements.
\end{abstract}

KEYWORDS

flash flood; flood risk; Clark method; hazard and risk mapping; river; Greece

\section{Introduction}

Among natural disasters, floods are the most frequent and destructive worldwide. Floods put human lives and property at risk, destroy infrastructures as well as agricultural and livestock facilities, induce intense soil erosion and pollution of water masses. According to Downton and Pielke (2001) and Golian et al. (2010) floods affect the greatest number of 
population and provoke the most damage of all natural disasters annually, while according to Pilon (2004) floods cause one third of the estimated losses due to natural catastrophes worldwide. According to insurance organizations worldwide, floods show significant rates amongst other types of disasters both in absolute event numbers, as well as with regard to financial losses. In particular, floods represent $26 \%$ of the number of large-scale catastrophic events between 1950 and 2002, as well as $8 \%$ of deaths and $27 \%$ of the economic damage caused by natural disasters, for the same period (Munich, 2002).

In the Greek region, floods are among the most significant natural, both in financial terms and in terms of human lives losses. According to Nikolaidou and Chatzichristou (1995) 216 people lost their lives between 1887 and 1994 in Greece. Apart from life loss, floods also have a significant impact on properties (houses, shops, industries), agriculture, livestock, infrastructure (structures, roads) and utility lines. In addition, there are important consequences on the environment although the magnitude of the impact has not been adequately investigated. One of the technical peculiarities of the Greek region is the lack of instrumental data especially with regard to the systematic recording of water courses' runoff. According to Stathis (2004) in the period 1980-2002, 114 of 150 floods occurred in ephemeral torrents traversing residential areas, while the remaining events occurred in more extensive hydrographic networks. The most recent catastrophic flood event occurred on November 2017 in Mandra (Western Attica, Greece), causing many fatalities as well as material damages (e.g. Andreadakis et al., 2018).

The management of flood risk, in recent years, has focused on approaches related to flood forecasting, early warning, land use planning and production of hazard maps (e.g. Lohani et al., 2014; Alfieri et al., 2014; Cools et al., 2016). At the same time structural and mechanical measures, such as dams, canals etc., have been viewed with scepticism due to the economic and environmental disadvantages (Golian et al., 2010).

During the last decades, flooding near the limits of residential areas has been increasing; according to Lekkas (2000) and Stathis (2004), the primary causes of this is the limitation of the streambeds (e.g. natural beds are replaced with artificial channels), the blocking of the riverbed, the decline of woodlands due to fires and the reduction of infiltration within the urban environment.

In this context, the objective of this paper is to study the phenomenon of flooding on the island of Naxos (Cyclades, Greece), assess the flood hazard and suggest actions to address flood risk. The availability of measurements concerning flood runoff is relatively limited in the Greek region and in southern Europe (Gaume et al., 2009). For this reason, hydraulic and hydrological methods have been employed for the calculation of hydrological parameters.

\section{Study area}

Naxos Island lies in the center of the Cycladic Islands complex with an area of $428 \mathrm{~km}^{2}$ (Fig. 1). The island constitutes part of the Atticocycladic unit, and it may be described as an elliptic dome, of NE direction, which consists mainly of metamorphic schist rocks, gneiss, marbles, Neogene and Quaternary deposits. In the core of the dome lies the migmatite intrusion.

The study area is the drainage basin of Paratrechos or Peritsi stream, which is located in the western part of Naxos Island (Figs. 1, 2). The catchment area of the stream is approximately $54 \mathrm{~km}^{2}$. The average elevation of the area reaches $245 \mathrm{~m}$, while the average slope of the basin is $21 \%$. The catchment area is drained by a medium to dense drainage system, which at some locations is characterized by meandering. Paratrechos or Peritsi stream is known to have caused severe problems following intense rainfall, with landslides in the mountainous areas, subsidence in large parts of the road network, and intense flooding events in the wider area of Chora, the island's capital city. This stream is very important as it is connected with the salt pit of Naxos, a well-known aquatic ecosystem on the island. Several floods have been recorded on Peritsi stream, with some recent events at the end of March 1998, beginning of January 1999, February 18, 2003, and February 4, 2011. 

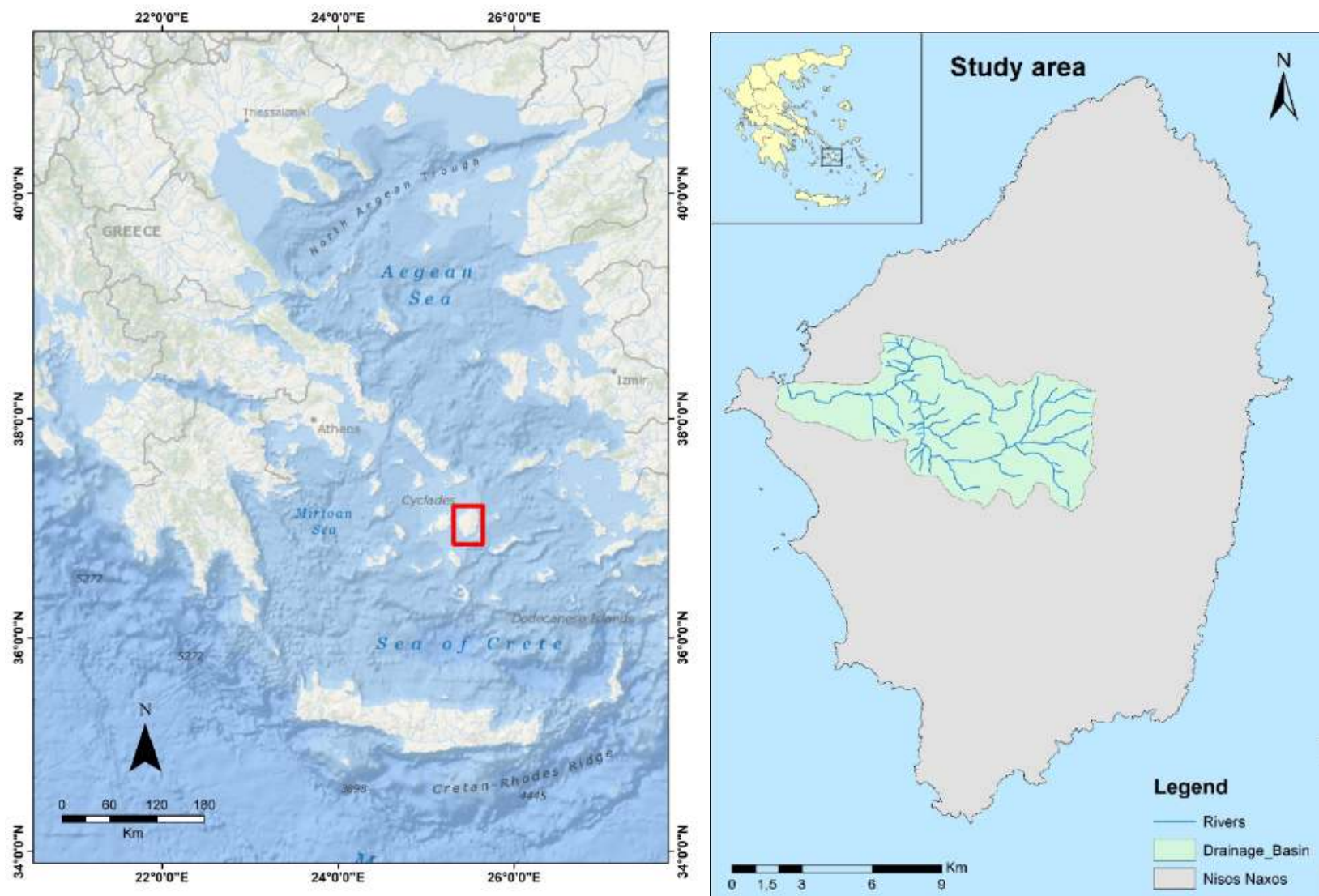

Figure 1 a) Location of Naxos Island, b) location of the studied hydrologic basin

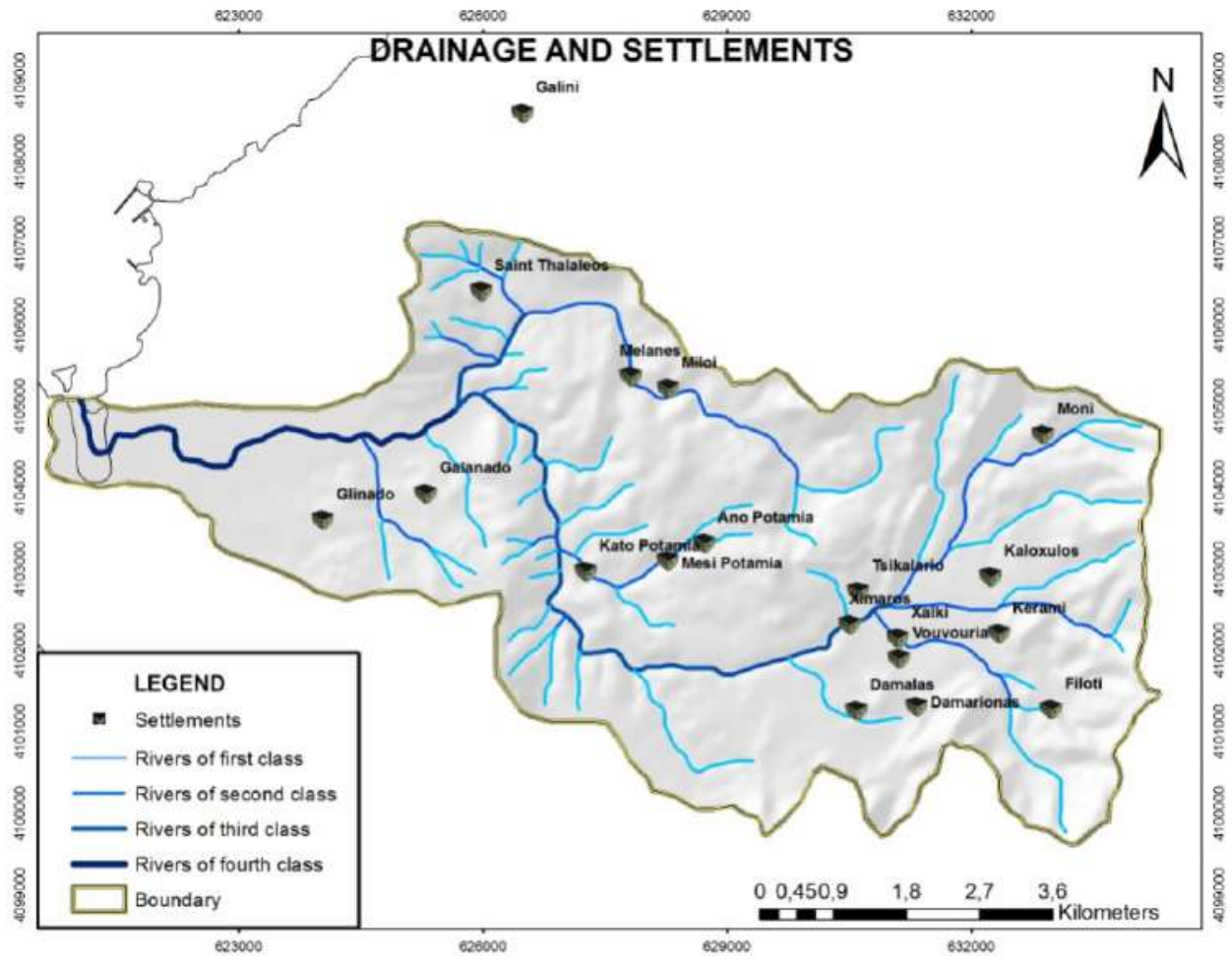

Figure 2 The studied drainage basin and the main settlements 


\section{Materials and Methods}

For the purposes of this work, the Clark method (e.g. Clark, 1945; Yang et al., 1999; Noorbakhsh et al., 2005; Bahram, 2005; Paudel et al., 2009) was selected amongst the available hydrological models, due to the quantity and quality of the data available for the study area. As already noted, there are no satisfactory data concerning the parameters required in most other hydrological models, such as river flows, spring discharge or groundwater levels and especially not for a sufficient timeline.

The Clark method produces Instantaneous Unitary Hydrographs (I.U.H.) for each drainage basin simulating two critical processes of transformation of excess rainfall to runoff. The maximum flow at the mouth of each sub-basin and the concentration time (the time rain water takes to reach the mouth of the basin) are calculated, in order to obtain the maximum discharge and produce the I.U.H. (Fig. 3).

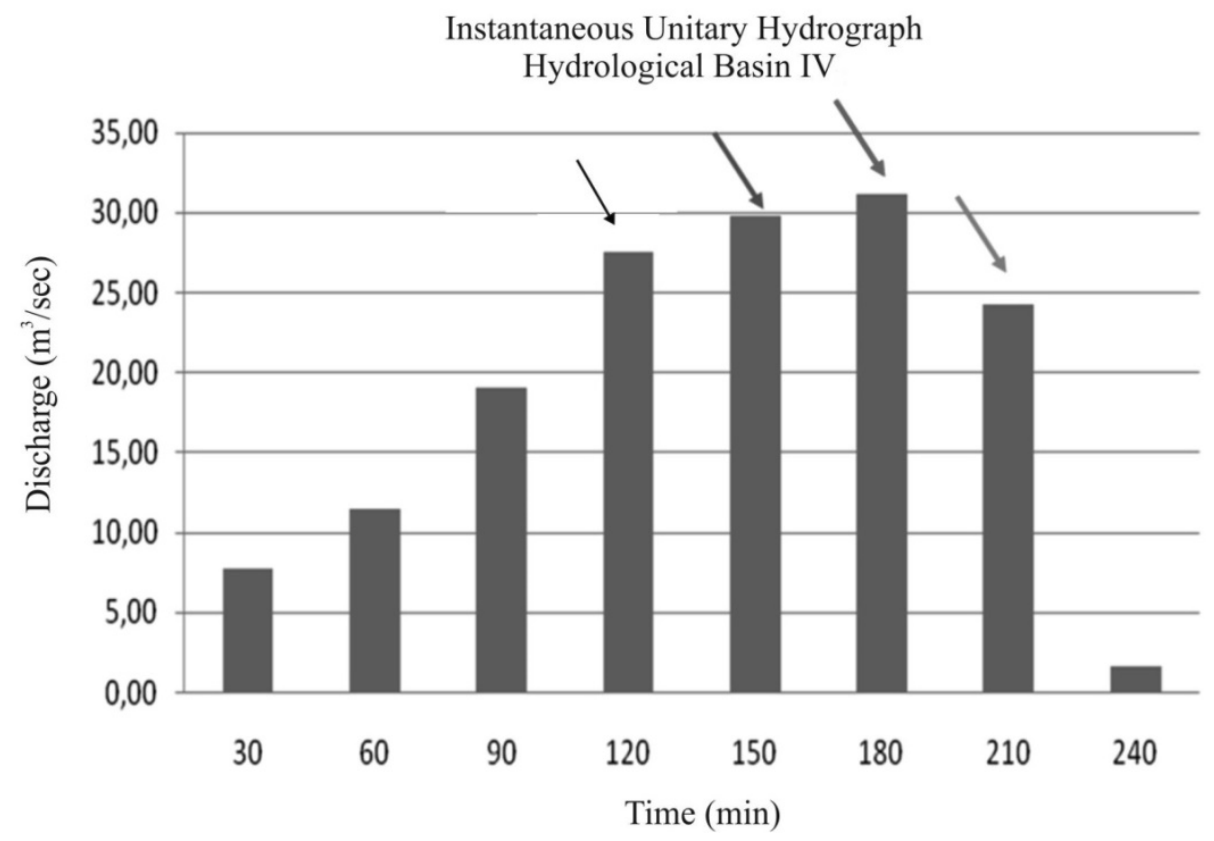

Figure 3 Instantaneous Unitary Hydrograph for drainage basin $\mathrm{IV}_{1}$

The calculation of the flood peak was based on the Natural Resources Conservation Service parametric model unit hydrograph (NRCS). The runoff curve number ( $C M$ is a coefficient that reduces the total precipitation to runoff potential, after subtracting evaporation, absorption, transpiration and surface storage for each sub-basin. The average value of $C N$ for the entire basin is estimated according to the following formula:

$C N=\frac{\sum_{i-1}^{n}\left(C N_{i}^{*} A_{i}\right)}{\sum_{i-1}^{n} A_{i}}$

where $A$ is the area of the sub basin in $\mathrm{km}^{2}$.

The concentration time $T c_{1}$, is the average time required for water to reach the farthest point of the basin to its orifice. In order to develop the I.U.H., the travel time grid file was divided in zones of equal time intervals, determined by the total concentra- tion time for the whole basin. The surface of each zone was estimated and the volume was calculated, by multiplying each surface by $0.001 \mathrm{~m}$, which is considered the amount of rain that falls in the catchment area, in a uniform way. The volume was used to calculate the discharge, which led to the creation of the I.U.H. (discharge in $\mathrm{m}^{3} / \mathrm{sec}$ by time in $\min )$.

The evaluation of the method was based on data derived from the installation of a hydrometric gauge and a weather station in the study area, in order to compare the peak periods of rainfall and water level. Data from three more weather stations, located within the drainage basin, were gathered and statistically processed in order to identify the period of highest precipitation and most frequently occurring flood events. 
The hydrometric gauge was placed below the new Peritsi Bridge, in the downstream area because all the 4th class stream waters accumulate at this point, the riverbed is well shaped and flood events have been recorded. Measurements of the water level were collected with a recording rate of $10 \mathrm{~min}$, over a period of four months (12/01/2011 to 19/05/2011), when the weather data indicated flood hazard is higher, in order to calculate the discharge. The flow velocity value that was used $(1.18 \mathrm{~m} / \mathrm{sec})$ was proposed for the specific location by Stamos and Danezis (2000).

\section{Results}

Figure 3 depicts the I.U.H. that was developed for the stream basin ( $4^{\text {th }}$ class-IV) of Peritsi, while table 1 shows the $\mathrm{CN}$, the average slope, the length of the main branch and the concentration time, as calculated for each basin $\left(4^{\text {th }}\right.$ class-IV and $3^{\text {rd }}$ class III1 and III2).

Based on the implementation in the study area, it was calculated that the time required for water to travel from upstream to the location of the hydrometric gauge is approximately three hours (163 $\mathrm{min}$ ), while the maximum discharge peak at that location is $40.71 \mathrm{~m}^{3} / \mathrm{sec}$.

Furthermore, according to fieldwork measurements and rainfall data, at the bridge where the hydrometric gauge is located, the water level rises three hours after a rainfall event upstream and the maximum discharge peak at the same location is $43.3 \mathrm{~m}^{3} / \mathrm{sec}$ (Table 2).

Hydrographs were constructed to show how water level increases at specific time periods upstream of the new Peritsi bridge, where the hydrometric gauge was placed. The $10 \mathrm{~min}$ time step recording of the water-level measurements was compared to precipitation events, provided by the local weather stations. These graphs are used to compute the actual time water takes to reach the point of the bridge from upstream in order to evaluate the results of the Clark method. Amongst the three flood events that were isolated (see Figure 3), the peak rainfall upstream was recorded about three hours earlier than the peak observed in the waterlevel measurements in the downstream region, i.e. at Peritsi bridge.

The conversion of the water level to discharge allows to compare the peak discharge from the field measurements with the one produced by the model. The greatest discharge was calculated at 43.3 $\mathrm{m}^{3} / \mathrm{sec}$ from a water level measurement recorded on February 4, 2011.

The study resulted in the production of a flood hazard map (Fig. 4), which depicts the three areas where risk is higher.

Table 1 Results of the Clark Method for the studied hydrologic basins

\begin{tabular}{ccccccccc}
\hline Class & $\begin{array}{c}\text { Curve } \\
\text { Number } \\
\text { CN }\end{array}$ & $\begin{array}{c}\text { Average } \\
\text { slope (\%) }\end{array}$ & $\begin{array}{c}\text { Average } \\
\text { Slope } \\
\text { (feet/feet) }\end{array}$ & $\begin{array}{c}\text { Branch } \\
\text { length } \\
\mathbf{( m )}\end{array}$ & $\begin{array}{c}\text { Branch } \\
\text { Length } \\
\text { (feet) }\end{array}$ & $\begin{array}{c}\text { Tc } \\
\text { (min) }\end{array}$ & $\begin{array}{c}\text { Tc } \\
\text { (hours) }\end{array}$ & $\begin{array}{c}\text { Maximum } \\
\text { discharge } \\
\left.\text { (m } \mathbf{m}^{\mathbf{3}} / \mathbf{s e c}\right)\end{array}$ \\
\hline IV & 77 & 21 & 0.21 & 19715 & 64682 & 213.41 & 3.56 & 31.13 \\
III2 & 76 & 23 & 0.23 & 13492 & 44265 & 155.04 & 2.58 & 28.73 \\
III1 & 80 & 23 & 0.23 & 9083 & 29800 & 100.14 & 1.67 & 11.89 \\
\hline
\end{tabular}

Table 2 Measured values from the hydrometric gauge installed at Peritsi stream

\begin{tabular}{ccc}
\hline \multicolumn{3}{c}{ Daily peaks per month } \\
\hline Date & Level $(\mathbf{c m})$ & $\begin{array}{c}\text { Discharge } \\
\left(\mathbf{m}^{\mathbf{3}} / \mathbf{s e c}\right)\end{array}$ \\
(dd/mm/yyyy) & 129 & 18.5 \\
$\mathbf{4} / \mathbf{2} / 2011$ & $\mathbf{2 4 1}$ & $\mathbf{4 3 . 3}$ \\
$8 / 3 / 2011$ & 115 & 15.42 \\
$3 / 4 / 2011$ & 91 & 10.11 \\
\hline
\end{tabular}




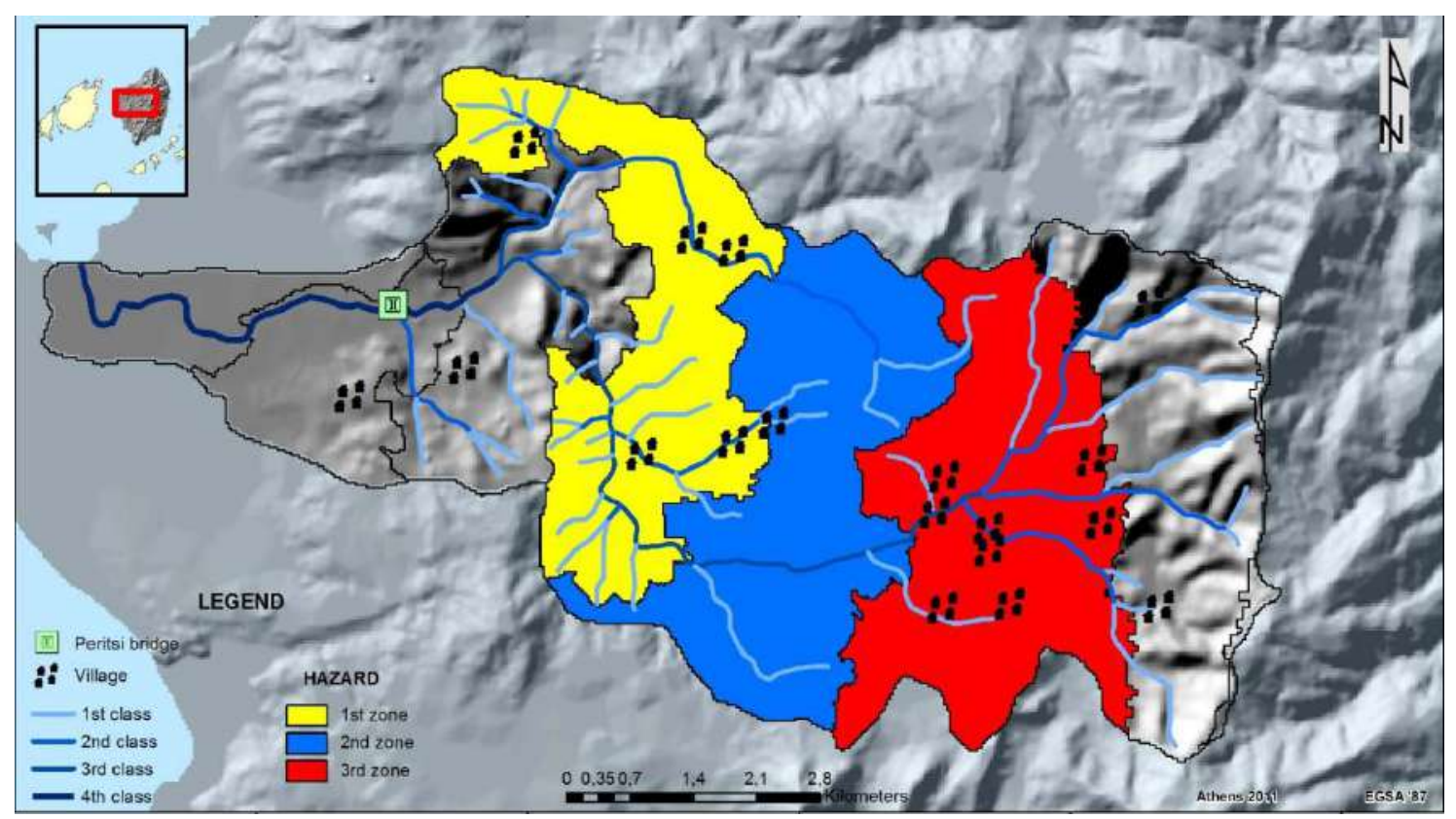

Figure 4 Flood hazard map of the study area

\section{Discussion}

Three main zones were distinguished (Fig. 4), whose characteristics constitute the cause of hazard at the mouth of the hydrologic basin. On the flood hazard map of Fig. 4, the three areas where risk is higher are indicated with three different color zones. A zone of very high risk (Fig. 4, $3^{\text {rd }}$ zone) is identified at the mountainous area in the eastern part of the basin, while the second and third zones are areas in the central part of the basin (Fig. $4,1^{\text {st }}$ and $2^{\text {nd }}$ zone). In these areas, the main elements responsible for the flood hazard at the mouth of the river basin (and for the flood peak) are the high topographic gradients, the shape of the basin, the shape of the morphological gradient, the geographical distribution of the hydrographical network and the soil (Fig. 4).

After the flood on February 18, 2003 landslides and subsidence of roads within the very high risk area were recorded, while areas located in the high risk zone caused overflow of the stream downstream. Areas downstream of the high risk area have suffered the greatest catastrophe, mainly in the first downstream area, where Peritsi bridge is located.

A comparison between the graphs of water level and rainfall has shown that, at the bridge, water level increases three hours after the rainfall incident upstream (Fig. 2).

By comparing the results of the model and the in situ measurements it was noted that the peak discharge of the model at the mouth of the 4th class basin is identical with the one obtained from the sum of peak discharge at the mouths of the two 3rd class sub-basins.

Flood risk management in the study area requires specific and clearly defined actions. For the slopes these actions could include vegetation covers, reduction of the slope's inclination or/and height, avoiding external loads at the body and the top of the slope, retaining measures, (shotcrete, construction of retaining walls at the base of the slope, etc.). For the arrangement of the stream's bed proposed solutions may include cleaning and restoring of the existing ditches from dense vegetation, pumping of water and removal of small damsobstacles. Finally, for the areas where flood risk is actually high a warning system is advisable to be installed.

\section{Conclusions}

Our study has shown that there are three main zones of flood hazard, at the study area of Paratrechos stream. The simulation of the study area and 
the respective results, have led to the conclusion that the time required for water to travel from upstream to the location of the hydrometric gauge is about three hours (163 $\mathrm{min})$, the maximum discharge peak at that location is $40.71 \mathrm{~m}^{3} / \mathrm{sec}$. According to fieldwork results and rainfall data, at the bridge, the water level rises three hours after a rainfall event upstream and the maximum discharge peak at the location of the hydrometric gauge is $43.3 \mathrm{~m}^{3} / \mathrm{sec}$. It should be noted that the results of the model were in very good agreement with in situ measurements; therefore it may be used to assess the discharge level. Last but not least, the study area has experienced catastrophic floods in the past and therefore specific and clearly defined actions are required for flood risk management. Our results have shown that the applied methodology may be used to assess the discharge level of a stream, and the acquired data may be further used to identify areas that will be affected and therefore propose and design specific actions and measures.

\section{References}

Alfieri L, Salamon P, Bianchi A, Neal J, Bates P, Feyen, L. 2014. Advances in pan- European flood hazard mapping. Hydrological processes, 28(13): 4067-4077. DOI: 10.1002/hyp.9947

Andreadakis E, Diakakis M, Nikolopoulos E, Spyrou, NI, Gogou, ME, Katsetsiadou, NK, Deligiannakis, G, Georgakopoulos, A, Antoniadis, Z, Melaki, M, Lekkas, E., Kalogiros, J. 2018. Characteristics and impacts of the November 2017 catastrophic flash flood in Mandra, Greece. EGU General Assembly 2018, Viena, 8 April.

Bahram S. 2005. Time-Area and the Clark Rainfall-Runoff Transformation. DOI: https://doi.org/10.1002/047147844X.sw1032

Clark CO. 1945. Storage and the Unit Hydrograph. Transactions of the American Society of Civil Engineering, 110: 1419-1446.

Cools J, Innocenti D, O'Brien S. 2016. Lessons from flood early warning systems. Environmental Science \& Policy, 58:117-22.

Downton MW, Pielke, RA Jr. 2001. Discretion without accountability: politics, flood damage, and climate. Natural Hazards Review, 2(4): 157-166.
Gaume $E$, Bain V, Bernardara $P$, Newinger $O$, Barbuc $M$, Bateman A, Blaškovičová L, Blöschl G, Borga $M, D u-$ mitrescu A, Daliakopoulos I, Garcia J, Irimescu A, Kohnova S, Koutroulis A, Marchi L, Matreata S, Medina V, Preciso E, Sempere-Torres D, Stancalie G, Szolgay J, Tsanis I, Velasco D, Viglione A. 2009. A compilation of data on European flash floods. Journal of Hydrology, 367: 70-78.

Golian S, Saghafian B, Maknoon R. 2010. Derivation of Probabilistic Thresholds of Spatially Distributed Rainfall for Flood Forecasting. Water Resources Management. DOI: 10.1007/s11269-010-9619-7

Lekkas E. 2000. Natural and technological disasters. 2nd Edition Access Pre-press, Athens, 278 p. (in Greek)

Lohani AK, Goel NK, Bhatia KK. 2014. Improving real time flood forecasting using fuzzy inference system. Journal of Hydrology, 509: 25-41.

Munich RE. 2002. Topics, an annual review of natural catastrophes. Munich Reinsurance Company Publications, Munich.

Nikolaidou M, Chatzichristou E. 1995. Recording and assessment of devastating floods in Greece and Cyprus. Diploma Thesis, Department of Water Resources, Hydraulic and Maritime Engineering, National Technical University of Athens (in Greek).

Noorbakhsh ME, Rahnama MB, Montazeri S. 2005. Estimation of Instantaneous Unit Hydrograph with Clark's Method Using GIS Techniques. Journal of Applied Sciences, 5(3): 455-458.

Paudel M, Nelson J, Scharffenberg W. 2009. Comparison of Lumped and Quasi-Distributed Clark Runoff Models Using the SCS Curve Number Equation. Hydraulic Engineering, 1098-1106.

DOI: 10.1061/(ASCE)HE.1943-5584.0000100

Pilon PJ. 2004. Guidelines for reducing flood losses. United Nations International Strategy for Disaster Reduction (UN/ISDR), Palais des Nations, Switzerland.

Stamos A, Danezis A. 2000. Study of flood protection works in regions of $S$. Greece. Flood protection works in the area of Peritsi bridge in Naxos Island. Athens.

Stathis D. 2004. Extreme rainfall events and flood genesis in Greece. Proceedings of the th Panhellenic Geografical Conference of the Hellenic Geographical Society, Mytilene, Greece, 1-8.

Yang MS, Kull W, Feldman AD. 1999. Evolution of Clark's unit graph method to spatially distributed runoff. Journal of Hydrologic Engineering, 4(1): 89-90. DOI: 10.1061/(ASCE)1084-0699(1999)4:1(89). 